\title{
Non-classical reproductive tract infections on the rise in women in Dschang, Cameroon
}

\author{
Catherine N.K. FUSI NGWA*, Vincent K. PAYNE and Augustine N. ASAKIZI \\ Department of Animal Biology, Faculty of Science, University of Dschang, P.O. Box 67, Dschang, \\ West Region, Cameroon. \\ *Corresponding author: Email: fncathkesah@yahoo.com
}

\begin{abstract}
Health promotion and education, wide coverage and pinpointing impediments to the realization of prevailing measures are among primary interventions for sexually transmitted infections (STIs). This work sought to establish STIs burden and related risk factors in women consulting gynecologists and general practitioners in some health centres in Dschang, Cameroon. For seven consecutive months, in a cross-sectional study, 1009 heterosexual women were examined; 353 (35\%) symptomatic patients aged 15-46 years (mean $31 \pm 3$.3years) consented and were interviewed using a questionnaire. Vaginitis was diagnosed by symptoms, positive cultures, and testing of blood and cervical specimens for antibodies to Treponema pallidum and Chlamydia trachomatis respectively. Infections recorded $45 \%$ under gynecological care and $14 \%$ for general consultations ( $p<0.001$ ), with an alarming $84 \%$ of general consultation cases without any intention of STIs screens or having future gynecologic appointments. Multiple sexual partners, early sexual debut, poverty, poor sanitation, recurrent infections, tight underwear, no barrier protection or irregular condom use and using chemicals in the vagina were recorded risks. Infectious vaginitis was identified in $300(30 \%)$ patients, 53(5\%) cases were non -infectious and 60\% had multiple infections. Bacterial vaginosis (28\%) and vaginal candidiasis (21\%) predominated. Rates for C. trachomatis, Neisseria gonorrhoeae, Trichomonas vaginalis, Phthirus pubis, infectious syphilis, genital warts and genital herpes were $<2 \%$. The present findings portrayed: STIs not given prime consideration under general practice, and a rising trend for non-traditional genital diseases due to poor hygiene and reproductive health knowledge deficiency. Health and sanitary campaigns, and mandatory gynecological exams for individuals of reproductive age were inevitable.
\end{abstract}

(c) 2012 International Formulae Group. All rights reserved.

Keywords: reproductive tract infections, women, pathogens, risk factors, prevention, Cameroon.

\section{INTRODUCTION}

Sexually transmitted infections (STIs), also known as sexually transmitted diseases (STDs) and venereal diseases (VDs) or vaginitis in women, have been defined as illnesses having a significant probability of being transmitted between humans by human sexual behaviour, including vaginal intercourse, oral sex and anal sex. Some STIs can also be contracted via childbirth, breastfeeding or the use of IV drug needles (Wikipedia, 2012). Until the 1990s, STIs were commonly known as STDs or VDs. Recently, the term sexually transmitted infections (STIs) is preferred and has broader meaning than STDs. Traditional or classical STIs have been 
long established i.e. for hundreds of years under the branch of medicine referred to as venereology, most commonly transmitted solely by sexual activity. Such typical STIs include bacterial, fungal, viral, parasitic and protozoal infections like chancroid (caused by Haemophilus ducreyi), chlamydia (Chlamydia trachomatis), granuloma inguinal or Klebsiella granulomatis, gonorrhoea (Neisseria gonorrhoeae), syphilis (Treponema pallidum), candidiasis, Hepatitis B virus, herpes simplex (Herpes simplex virus 1,2), AIDS (HIV), Human papillomavirus, genital warts, molluscum contagiosum, pubic lice (Phthirus pubis), scabies (Sarcoptes scabiei) and trichomoniasis (Trichomonas vaginalis). Over time, new or atypical pathogens have been implicated in STI etiology particularly related to bacterial vaginosis owing to high standards of medical technology, travel, invasive procedures, poor hygiene and sanitation, immunosuppression, antibiotic resistance and therapy across board, anthropogenic changes, climate change and genital practices which affect reproductive health (Adad et al., 2001; STD statistics worldwide, 2011; Hodowanec et al., 2012).

Reproductive health ensures a vibrant labour force and sustainable development. STIs or reproductive tract infections remain a growing problem for humans affecting people of all ages, backgrounds and works of life, with poor sexual health impacting most in young heterosexuals and in men who have sex with men (Ndongmo et al., 2003; Mbu et al 2005; Shiely et al., 2010; Malacova et al., 2011; Health Protection Report, 2012a and 2012b; Hodowanec et al., 2012). Getting facts about such problems and reproductive health is increasingly important since there is a need to constantly educate the society of associated dangers, initiate new and scale up existing interventions, and strategize for valuable future management programs (Mayaud and McCormick, 2001; Mayaud and Mabey, 2004; Genuis and Genuis, 2005). Clearly, STIs have resulted in untold misery world wide. An estimated $75 \%$ of women develop vaginitis at some point in their lives, and about 4 in 10 become infected more than once (Adad et al., 2001). Although STIs have been caused by pathogenic bacteria, parasites, yeasts and viruses; there is non-infectious vaginitis which involves irritations or allergic reactions from chemicals that are present in vaginal products and contaminated clothing that is in contact with the genital area or a decrease in hormones because of menopause or surgery that removes the ovaries (Mbizvo et al., 2001). Over time, inconsistent condom use, homosexuality or overlapping sexuality, poverty, many sex partners, prostitution, infidelity, teenage sex, juvenile delinquency, ignorance and inadequate healthcare have been related to increased rates of STIs (Ndongmo et al., 2003; Mbu et al., 2005; Oster, 2005; The Oklahoma, 2008; Dia et al., 2010; Shiely et al., 2010; Health Protection Agency, 2012a and 2012b). In various communities, the transmission of STIs has been effected by both symptomatic and asymptomatic individuals (Wilkinson et al., 1997; Mbizvo et al., 2001; Garcia et al., 2007). Colossal strides have been made in STI prevention and control including easy access to sexual and reproductive health services, greater STI screening, regular or annual screens for the sexually active, case finding and management among vulnerable groups, targeted periodic mass therapy, encouraging safer sexual behaviour, avoiding overlapping sexual relationships, consistent condom use, few sexual partners, requisite healthcare and facilities, and identifying barriers to prevention and control (Mayaud and McCormick, 2001; Mayaud and Mabey, 2004; Oster, 2005; Garcia et al., 2007; Health Protection Report, 2012a and 2012b; Hodowanec et al., 2012).

Genital infections have become a huge health problem in Cameroon with devastating consequences. Premature deaths, destabilization of the family, increased number of orphans, increased medical and funeral expenses, increased absenteeism from work, decreased productivity and massive loss of jobs, reduction of qualified manpower, increased misery and poverty are very glaring. 
The management of such infections has been complicated by difficulties to change deeply cultivated sexual behaviour and attitude among the infected, the affected and the uninfected. In some parts of the country, most often, treatment has not been sufficient or readily available (Ndongmo et al., 2003; Genuis and Genuis, 2005; Mbu et al., 2005; Dia et al., 2010; Henry et al., 2010).

There is a dearth of knowledge on the aetiology of genital infections in Dschang. Thus, in line with global prevention efforts, the present investigation was undertaken to elucidate the types, pathogens and risk factors of vaginitis in Dschang among symptomatic individuals, as an attempt to document the burden and peculiarities in the causation of STIs, and create awareness as a means of fostering empowerment and to contain related mishaps that plague society, learning more about genital infections helps especially the woman or the girl child to better arm herself for the future.

\section{MATERIALS AND METHODS \\ Patients/Study centres}

Sick women included in this study visited some healthcare centres in Dschang for gynecologic and general consultation (Table 1). The Chief Medical Officers or Heads of these health institutions were officially informed about the study, which was subsequently endorsed and consulting clinicians or nurses notified. Each centre was visited once a week for data and sample collection from June to December, 2009.

\section{Ethical clearance}

Authorization to carry out this work was obtained form the Chief Medical Officer of Menoua Division.

\section{Administration of questionnaires}

Detailed information relevant to the study was collected from each patient by the examining medical personnel using the researchers' questionnaire. Such data included the age, area of residence, religion, tribe, marital status, type of marriage, occupation and that of spouse, the number of sexual partners, whether or not the patient was a commercial sex worker, underlying clinical condition, whether or not a patient has suffered from a genital infection in the past, vaginal morphology and the presence or absence of discharge. Other data collected were the use of preservatives, contraceptives, antibiotics and tight-fitting synthetic abovethe-knee fashionable panty-hose without a cotton panel popularly referred to as "coolant" or "cyclise". More data were collected on genital hygiene-whether or not the patient uses soap particularly medicated soap or antiseptics for bathing the outer genitalia, whether or not the patient douches and the types of douching ingredients.

\section{Collection of samples}

Cervical swabs were collected from all symptomatic cases by a laboratory worker, the consulting nurse or clinician. Two swabs were collected per patient-one for a direct examination, and the second for culture and serology. Blood was collected from 12 patients suspected for syphilis and tested for antibodies to Treponema pallidum. All specimens were packed in leak-proof plastic bags and immediately transported to the laboratory of Applied Biology and Ecology of the Department of Animal Biology of the University of Dschang for analysis.

\section{Processing of specimens}

All specimens were processed according to recommended techniques (Murray et al., 1995). The pH of each sample was determined using the swab specimen for direct examination. The second cervical swab was cultured on a set of blood, chocolate, MacConkey and Sabouraud Dextrose agar media. One set each of blood and chocolate agar plates were incubated in an atmosphere of enhanced carbon dioxide (5-10\%), that is, in a candle extinction jar for 24-48 hours at 37 ${ }^{\circ} \mathrm{C}$. The second set of blood and chocolate agar plates were incubated anaerobically at 37 ${ }^{\circ} \mathrm{C}$ using a Gas-Pak anaerobic jar (BBL anaerobic systems) with a palladium catalyst 
and a gas generating kit. The MacConkey agar plates (only one plate of this medium was used per patient) were incubated in air at 37 ${ }^{\circ} \mathrm{C}$ for $24-48$ hours. One set of Sabouraud Dextrose agar was incubated at $37^{\circ} \mathrm{C}$ for up to 7 days, while the second set of plates for this medium was incubated at room temperature (25-30 ${ }^{\circ} \mathrm{C}$ ) for up to 14 days. Gram staining and biochemical tests including the germ tube test for yeasts were used to identify isolates. Streptococci and enterococci were identified by Lancefield grouping.

The presence of Chlamydia trachomatis infection was tested using the CHLAMY-CHECK-I kit (KENZA DIAGNOSTICES, KYA SAND). The Rapid Plasma Reagin (RPR) test and the Wellcosyh HA 100 VD B5 8E 59-01 kit were used to detect $T$. pallidum.

\section{Statistical analysis}

A two sample t test in Genstat 9.2 for windows was used to compare means of infections.

\section{RESULTS}

The study involved 1009 heterosexual women with ages ranging between 15 and 65 years (mean 33.13 \pm 8.4 years) who visited some health centres in Dschang for care. Many more women consulted gynecologists $(60.2 \%)$ than general practitioners (Gyps) (39.8\%). In total, 353 symptomatic women,

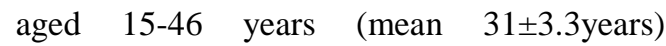
characterized by vaginal discharge and /or bleeding with one or more of the following symptoms: vaginal soreness, irritation or itching, rashes, warts or maps (white patches), lice on the vulva, pain or discomfort during sexual intercourse, abdominal pain and burning during urination (dysuria); gave their consent to the study. The percentage of SV under gynecologic care $(45.25 \%)$ was significantly $(\mathrm{p}<0.001)$ higher than that under general consultation (14.12\%). Fifty-two (83.9\%) symptomatic patients established consulted Gyps primarily for other health issues than those of the genital tract, and did not intend to test for STIs nor had any planned gynecologic appointments.

Analysis of information obtained from the questionnaires revealed that vaginitis was no respecter of age, profession, background, vocation, place, religion or ethnic group. Due to multiple sexual partners, the 15-25 and the 31-35years age groups, students, women in polygamous marriage or women married to drivers or frequent travellers and those who had extra-marital affairs were slightly more vulnerable to vaginitis. Women with new sexual partners, those with a history of prior or recurrent genital infections, those who douched with chemicals or used medicated soap or antiseptics to wash the vagina and a few commercial sex workers identified in the study population were also hard hit. Though a limited population was examined, widows and divorcees were highly susceptible. Antibiotic therapy, constant wearing and exchange of synthetic fashionable tights, the non-usage of condoms, not screening new partners before intercourse, and sexual promiscuity or prostitution were other risk factors identified.

Significant growth of pathogens was identified in 300 cases, giving a rate of $29.7 \%$ infectious vaginitis in the 1009 initial study popualtion, $53(5 \%)$ patients were noninfectious. The $\mathrm{pH}$ of the cervical swabs ranged from 3.5 to 8.5 for infected specimens and from 3.7 to 4.5 for samples void of pathogens. A total of 579 types of vaginitis were identified in the 353 women (Table2). Only $142(4.1 \%)$ patients had one type of vaginitis. Many $207(20.5 \%)$ of the infected patients had two types of vaginitis, while three types were identified in only $4(0.4 \%)$ patients.

Bacterial vaginosis $(6 \%)$ and yeast vaginitis $(2 \%)$ singly and in combination $(18.4 \%)$ predominated $(\mathrm{p}<0.05)$. Majority of the patients with bacterial vaginosis, yeast vaginitis and Chlamydia were highly associated with past genital infection, poor personal and environmental hygiene which led to the use of chemicals in the vagina, constant wearing and exchange of tights without frequent washing, antibiotic therapy and sexual promiscuity or prostitution,. 
A total of $538(53.8 \%)$ pathogens from 16 genera were identified in the 300 infectious cases (Table 3). Eighty-nine (8.8\%) cervical samples habored one pathogen, while two or more pathogens were identified in 211 specimens. Candida albicans had $19.5 \%$ isolation $(\mathrm{p}<0.05)$, a rate twice higher than that for Staphylococcus aureus (8.2\%) and
Escherichia coli $(8.1 \%)$ which ranked second and third in prevalence respectively. Rates were $<2 \%$ for traditional pathogens. $C$. albicans and S. aureus 49(4.9\%), C. albicans and $E$. coli $35(3.5 \%)$, and $C$. albicans, $S$. aureus and $C$. trachomatis $2(0.2 \%)$ occurred most in mixed cultures.

Table 1: Incidence of Symptomatic Vaginitis in the study population.

\begin{tabular}{|c|c|c|c|c|c|c|}
\hline \multirow[t]{3}{*}{ Health centres } & \multicolumn{6}{|c|}{ No of Patients examined } \\
\hline & \multicolumn{2}{|c|}{ Gynecologic care } & \multicolumn{2}{|c|}{ General consultation } & \multirow[t]{2}{*}{ Total } & \multirow{2}{*}{$\begin{array}{l}\text { No (\%) with } \\
\text { SV }\end{array}$} \\
\hline & $\mathrm{N}$ & No (\%) with SV & $\mathrm{N}$ & No (\%) with SV & & \\
\hline \multicolumn{7}{|l|}{ Dschang District } \\
\hline Hospital & 394 & 181(45.9) & 155 & $27(17.4)$ & 549 & 208(37.9) \\
\hline $\begin{array}{l}\text { Hospital Saint Vincent } \\
\text { de Paul }\end{array}$ & 150 & $83(55.3)$ & 119 & $18(15.1)$ & 269 & 101(37.5) \\
\hline Fiangep Polyclinic & 36 & $15(41.7)$ & 51 & $9(17.6)$ & 87 & $24(27.6)$ \\
\hline Clinique Bienveillance & & & & & & \\
\hline de Foto & 18 & $9(50)$ & 40 & $6(15.0)$ & 58 & $15(25.9)$ \\
\hline Centre de Santé Fometa & 9 & $3(33.3)$ & 37 & $2(5.4)$ & 46 & $5(10.9)$ \\
\hline Total & 607 & 291(47.9) & 402 & $62(15.4)$ & 1009 & $353(35.0)$ \\
\hline
\end{tabular}

Table 2: Types of Vaginitis identified in the Study Population.

\begin{tabular}{lc}
\hline Type of Vaginitis identified & No $(\%)$ recorded $(\mathbf{n = 1 0 0 9 )}$ \\
\hline Bacterial vaginosis & $279(27.7)$ \\
Yeast vaginitis & $211(20.9)$ \\
Chlamydia & $11(1.1)$ \\
Gonorrhoea & $7(0.7)$ \\
Trichomonas vaginitis & $7(0.7)$ \\
Genital warts & $4(0.4)$ \\
Pediculosis (Pubic lice) & $3(0.3)$ \\
Active syphilis & $2(0.2)$ \\
Genital herpes & $2(0.2)$ \\
Non- infectious vaginitis & $53(5.3)$ \\
\hline
\end{tabular}


Table 3: Aetiologic Agents of Vaginitis identified in Study subjects.

\begin{tabular}{lc}
\hline Pathogens & Total No (\%) identified (n=1009) \\
\hline Candida albicans & $197(19.5)$ \\
Staphylococcus aureus & $83(8.2)$ \\
Echerichia coli & $82(8.1)$ \\
Proteus mirabilis & $41(4.1)$ \\
Gardnerella vaginalis & $26(2.6)$ \\
Enterobacter spp. & $15(1.5)$ \\
Sporothrix schenkii & $14(1.4)$ \\
Klebsiella pneumoniae & $10(1.0)$ \\
Chlamydia trachomatis & $11(1.1)$ \\
Pseudomonas aeruginosa & $10(1.0)$ \\
Streptococcus pyogenes & $8(0.8)$ \\
Enterococcus spp. & $8(0.8)$ \\
Neissera gonorrhoeae & $7(0.7)$ \\
Trichomonas vaginalis & $7(0.7)$ \\
Pseudomonas spp. & $6(0.6)$ \\
Phthirus pubis & $3(0.3)$ \\
Streptococcus agalactiae & $3(0.3)$ \\
Treponema pallidum & $2(0.2)$ \\
Klebsiella spp. & $2(0.2)$ \\
\hline
\end{tabular}

\section{DISCUSSION}

In the present study, the screening of 353 women with SV in some health institutions in Dschang gave a proportionate infectious rate of $85 \%$, with bacterial vaginosis and yeast vaginitis significantly on the lead. These results conform with findings in Brazil (Adad et al., 2001) and in Zimbabwe (Mbizvo et al., 2001) and tend to agree with reports that although yeast is the name most women know and think about when they hear of vaginitis, bacterial vaginosis is actually the most common vaginal infection in women of reproductive age. Traditional STIs recorded very low rates in this study and similar results are reported elsewhere (Stauffer et al., 2012; Varma, 2012). Chlamydia has been reported to be increasing in older women, while syphilis is on the decline (Chiduo et al., 2012; Cumming et al., 2012).

Some 53 patients (5\%) who had common symptoms of vaginitis such as itching, burning and vaginal discharge did not harbour any causative agents. However, most of these patients douched with chemicals or made use of medicated soap or antiseptics for genital hygiene. Thus, vaginitis in such cases might have been caused by allergies or irritations resulting in the loss of normal vaginal $\mathrm{pH}$. Chemicals in medicated soap or antiseptics, and bleach in water or clothes or inner wears not thoroughly rinsed out may harm friendly bacterial in the genitalia that check yeast. In this study population, douching might have accounted for the marked deviation of vaginal $\mathrm{pH}$ from the normal acid range of 3-3.5 to 3.6-8. This can in turn lead to an alteration in the natural organisms in the vagina thereby favouring the growth of yeasts and other pathogens. The wearing of synthetic under wears or tight clothing could generate heat in the genital region which also favours the growth of yeasts and other pathogens. In Dschang generally 
speaking, due to non-constant flow of pipe borne water which often leads to poor personal and environmental hygiene, the use of medicated soap or antiseptics for bathing or the addition of chemicals such as bleach or mercryl to bathing water is common place. This habit is hereby discouraged as it could be greatly contributing to genital infections in this locality.

Other risk factors of vaginitis identified in this study were early engagement in sexual life for pleasure, procreation or to make ends meet without using preservatives and without screening partners; having multiple sexual partners; past genital infections, constant wearing and exchange of tights; and antibiotic therapy. Despite the enormous sensitization on venereal diseases particularly on HIV/AIDS in the last two decades, the behaviour of study respondents towards these diseases did not seem to have changed much. These findings are in accordance with reports in other countries (Ekert et al., 1998; Reed et al., 2000; Sullam et al., 2001; Kalinka et al., 2003; Ward and Day, 2006; Chiduo et al., 2012; Shao and Williamson, 2012). Else where, infectious vaginitis has been attributed to the use or insertion of leaves and other materials into the vagina to boost male sexual pleasure, frequent intercourse (more than four times a month), and oral-genital -anal contact (Wilkinson et al., 1997). In this study, students were highly vulnerable to vaginitis probably due to no resources to treat themselves, unlike the civil servants who could easily treat themselves and recorded lower infection rates. The findings obtained herein further indicated that genital diseases were not given due consideration or priority attention under general consultation, thus gynecological care is encouraged for all females of reproductive age. Also, health campaigns to arouse public interest of the morphology and functioning of the reproductive tract, and recognition and reporting of changes were deemed necessary. STIs prevention through delayed sexual debut and partner reduction was also encouraged.

In most developing countries, drug abuse is rampant and it is not unusual for patients to stop medication as soon as symptoms disappear without taking the full dose (Kesah et al., 1999). Thus, it was not surprising that some patients with recurrent vaginitis in this study were at high risk since some actually confessed poor drug compliance and the use of herbal concoctions for treatment. The leading pathogens identified in this study were $C$. albicans, S.aureus and E.coli. These results compare favourably with other studies (Wilkinson et al., 1997; Shafer et al., 1985; De Seta et al., 2000; Bayo et al., 2001). The traditional sexually transmissible pathogens are easily treated nowadays, thus, it was not surprising that their prevalence was very low in this study. Poor personal and environmental hygiene might have exposed some patients to infections with Sporothrix schenckii. In Dschang, many people out doors tend to urinate and/or defaecate in open environments due to the deplorable state or absence of public toilets, thereby exposing the vagina to contamination. As a matter of fact, municipal water supplies are often interrupted partly due to incessant light cuts and/or rationing so much so that environmental hygiene particularly in homes and institutions needs to be periodically examined as of old by community leaders and sanitary inspectors.

Since vaginitis can have many causes, a clinical examination and laboratory tests are necessary for accurate diagnosis of the cause of symptoms. There is a great need to continuously educate or inform society, especially the girl child or women in the Dschang community on the aetiology of genital infections, their impending dangers and preventive measures. The present findings were disseminated at the various study centres 
hoping that they would inform and contribute to the optimal management of vaginitis in Dschang. Further studies, taking into account asymptomatic cases and antibiotic abuse were embarked on to further expatiate on the risk of exposure of the population to genital infections.

\section{ACKNOWLEDGEMENTS}

The authors are very grateful to the staff of the various health centres visited for their cooperation which made this work possible; and to Mrs Katte Bridget of the Department of Animal Production, Faculty of Agriculture and Agricultural Sciences for technical assistance.

\section{REFERENCES}

Adad SJ, de Lima RV, Sawan ZT, Silva ML, de Souza MA, Saldanha JC, Falco VA, da Cunha AH and Murta EF. 2001. Frequency of Trichomonas vaginalis, Candida sp. and Gardnerella vaginalis in cervical - vaginal smears in four different decades. Sao Paulo Med. J., III9(6): 200 -205 .

Bayo M, Berlanga M, Agut M. 2001. Vagina microbiota in healthy pregnant women and prenatal screening of group B streptococci (GBS). Int. Microbiol., 5(2): 87-90.

Chiduo M, Theilgaard ZP, Bakari V, Mtatifikolo F, Bygbjerg I, Flanholc L, Gerstoft J, Christiansen CB, Lemnge M and Katzenstein TL. 2012. Prevalence of sexually transmitted infections among women attending antenatal clinics in Tanga, North Eastern Tanzania. Int J STD AIDS, 23(5): 325-329.

Cumming GP, Cochrane R, Currie HD, Moncur R, Lee AJ. 2012. Web-based survey 'contraception and attitudes to sexual behaviour completed by women accessing a UK menopause website.
Menopause International - Journal, 18(3): 106-109.

De Seta F, Piccoli M, De Santo D, Sartore A, Grimaldi E, Panerari I, Ricci G, Guaschino S. 2000. Sexually transmitted diseases in adolescence. Minerva Ginecol., 52(12): 19-24.

Dia A, Marcellin F, Bonono RC, Boyer S, Bouhnik AD, Protopopescu C, KoullaShiro S, Carrien MP, Abe C, Spire B and the EVAL Study Group. 2010. Prevalence of unsafe sex with one's steady partner either HIV-negative or of unknown HIV status and associated determinants in Cameroon (EVAL ANRS 12-116 Survey). Sex. Transm. Infect., 86: 148-154.

Eckert LO, Hawes SE, Stevens CE, Koutsky LA, Eschenbach DA, Holmes KK. 1998. Vulvovaginal candidiasis: Clinical manifestations, risk factors, management algorithm. Obstet. Gynecol., 92(5): 757765.

Garcia PJ, Carcamo CP, Chiappe M, Holmes KK. 2007. Sexually transmitted and reproductive tract infections in symptomatic clients of pharmacies in Lima, peru. Sex. Transm. Infect., 83: 142146.

Genuis SJ, Genuis SK. 2005. Primary prevention of sexually transmitted disease: applying the ABC strategy. Review Postgrad. J., 81: 299-301.

Health Protection Report 2012a. Sexually transmitted infections in England, 2011. Health Protection Report 69220, 1 June 2012.

Health Protection Report 2012b. Genital Chlamydia trachomatis tests and diagnoses in young adults in England, 2011. Health Protection Report 69220, 1 June 2012.

Henry E, Marcellin F, Yomb Y, Fugon L, Nemande S, Gueboguo C, Larmarange J, Trenado E, Eboko F, Spire B. 2010. 
Factors associated with unprotected anal intercourse among men who have sex with men in Douala, Cameroon. Sex. Transm. Infect., 86: 136-140.

Hodowanec A, Nayak S, Charurat M, Vaughan L, Kanno M, Fantry L. 2012. Prevalence of asymptomatic bacterial sexually transmitted infections in hospitalized HIV patients in Baltimore city. Journal of the International Association of Physicians in AIDS Care (JIAPAC), 11(1): 16-19.

Kalinka J, Laudanski T, Hanke W, Wasiela M. 2003. Do microbiological factors account for poor pregnancy outcome among unmarried pregnant women in Poland? Fetal Diagn. Ther., 18(5): 34552.

Kesah CN, Egri-Okwaji MTC, Odugbemi TO, Iroha EO. 1999. Resistance of Nosocomial Pathogens to commonly used antimicrobial agents. The Nigerian Postgraduate Medical Journal., 6(2): 1-5.

Malacova E, Butler T, Richters J, Yap L, Grant L, Richards A, Smith AMA, Donovan B. 2011. Knowledge of sexually transmitted diseases: a comparison of prisoners and the general population. Int $J$ STD AIDS., 22(7): 381-386.

Mayaud P , Mabey D. 2004. Approaches to the control of sexually transmitted infections in developing countries: old problems and modern challenges. Sex. Transm. Infect., 80: 174-182.

Mayaud P, McCormick D. Interventions against sexually transmitted infections (STI) to prevent HIV infection. 2001. Br. Med. Bull., 58(1): 129-153.

Mbizvo EM, Msuya SE, Stray-Pedersen B, Sundby J, Chirenje ZM, Hussain A. 2001. Determinants of reproductive tract infections among asymptomatic women in Harare, Zimbabwe. Cent. Afr. J. Med., 47(3): $57-64$.
Mbu RE, Mbopi-Keou FX, Alemdji G, Meli C, Eteki N, Nkengasong N, Belec L and Leke RJ. 2005. Unexpected high prevalence of sexually transmitted diseases in married women attending family planning clinics in Yaounde, Cameroon. Int. J. STD AIDS., 16: 270271.

Murray PR, Baron EJ, Pfaller MA, Tenover FC, Yolken RH. 1995. Manual of Clinical Microbiology (6 ${ }^{\text {th }}$ edn). ASM Press: Washington, DC; 1482p.

Ndongmo CB, Zekeng L, Kaptue L. 2003. Increased HIV prevalence among individuals attending a sexually transmitted infection clinic in Yaounde, Cameroon. Int. J. STD AIDS., 14(3): 189192.

Oster E. 2005. Sexually transmitted infections, sexual behaviour and the HIV/AIDS epidemic. The Quarterly Journal of Economics., 120(2): 467-515.

Reed BD, Gorenflo DW, Gillespie BW, Pierson CL , Zazove P. 2000. Sexual Behaviours and other risk factors for Candida vulvovaginitis. J. Women's Health Gend. Based Med., 9(6): 645-655.

Shafer MA, Sweet RL, OhmSmith MJ, Shalwitz J, Beek A, Schachter J. 1985. Microbiology of the lower genital tract in Post-menarchal adolescent girls: differences by sexual activity, contraception and presence of non specific vaginitis. J. Pediatr., 107(6): 974-981.

Shao Y, Williamson C. 2012. The HIV-1 epidemic: Low-to -middle income countries. Cold Spring Harb Perspect Med. Mar., 2(3): a007187.

Shiely F, Horgan M, Hayes K. 2010. Increased sexually transmitted incidence in a low risk population: identifying the risk factors. Eur. J. Public Health., 20(2): 207-212. 
Stauffer WM, Painter J, Mamo B, Kaiser R, Weinberg M, Berman S. 2012. Sexually transmitted infections in newly arrived refugees: is routine screening for $\mathrm{N}$. gonorrhoeae and Chlamydia trachomatis infection indicated. Am. J. Trop. Med. Hyg., 86(2): 292-295.

STD Statistics Worldwide Avert.org. Retrieved, 2011-01-09.

Sullam SA, Mahfouz AA, Dabbous NI, elBarrawy M, el-Said MM. 2001. Reproductive tract infections among married women in Upper Egypt. East Mediterr. Health J., 7(1-2): 139-46

The Oklahoma. 2008. CDC study says at least 1 in 4 teen girls has a sexually transmitted disease; Human papilloma virus most common.
Varma R. 2012. Women requiring emergency contraception are a high risk group for sexually transmitted infections in future. Sex Transm Infect., 88: A42.

Ward H, Day S. 2006. What happens to women who sell sex? Report of a unique occupational cohort. Sex. Transm. Infect., 82: $413-417$.

Wikipedia, the free encyclopedia, 30 August, 2012. http://en.wikipedia.org/wiki/ sexually_transmitted-disease.

Wilkinson D, Ndovela N, Harrison A, Lurie M, Connolly C, Sturm AW. 1997. Family Planning Services in developing countries: an opportunity to treat asymptomatic and unrecognized genital tract infections. Genitourin. Med., 73(6): 558-560. 